\title{
Matrix effects during trace elements analysis in plant samples by inductively coupled plasma atomic emission spectrometry with axial view configuration and ultrasonic nebulizer
}

\author{
P. Masson*, D. Orignac, A. Vives and T. Prunet \\ Unité d'Agronomie, Centre de recherches INRA de Bordeaux, B.P. 81, 33883 Villenave d'Ornon Cedex, France
}

\begin{abstract}
Plant matrix effects have been characterized during trace element analysis by axial view inductively coupled plasma atomic emission spectrometry with ultrasonic nebulizer. Six elements were studied: $\mathrm{As}, \mathrm{Cd}, \mathrm{Co}, \mathrm{Cr}, \mathrm{Ni}$, and $\mathrm{Pb}$. The interferences were simulated by measuring analyte signals on solutions containing various concentrations of elements encountered in mineralized plant samples such as $\mathrm{K}, \mathrm{Ca}, \mathrm{Mg}, \mathrm{P}, \mathrm{Na}, \mathrm{Fe}$ and $\mathrm{Mn}$. Signal suppression is observed for the ionic lines and signal enhancement occurred for atomic lines. The effects were found to be caused by particles and easily ionizable elements (EIEs) into the central channel of the plasma. The particle vaporization led to lower plasma temperatures and decreased emission intensities. EIEs changed the ion/atom ratio toward atom and improved the atomic emission intensities. Use of a plant sample on the analytical signal of trace elements led to same conclusions. The matrix effects can be removed by using high generator power especially for the ionic spectra lines.
\end{abstract}

Keywords. Inductively Coupled Plasma Atomic Emission Spectrometry - ultrasonic nebulizer - matrix interference - plant sample analysis - traces analysis - heavy metals.

\section{Introduction}

Since many years, inductively coupled plasma atomic emission spectrometry (ICP-AES) is becoming a widely used technique to determine the levels of major elements in plant samples after acid dissolution [1-4]. Nevertheless, smallest detection limits are required for analysis of trace element concentrations. The recent developments in instrumentation with axial view configuration allow an improvement in sensitivity [5-9]. The plasma volume observed is many times larger compared to the radial-view systems. Davis and Dean reported five to ten fold improvement in the detection limits [8]. However, the performances of an axial ICP equipped with pneumatic nebulizer are just acceptable for routine trace element measurements in plant samples [9]. For some analytes such as $\mathrm{Cd}, \mathrm{Pb}$ or As, concentration values in plant tissues could be sometimes below the detection limits. The main limitation is the low sample introduction efficiency. Only a relatively small fraction (2-3\%) of the sample solution is converted to the very fine aerosol that ultimately reaches the plasma. The use of an ultrasonic nebulizer (USN) may increase the emission signals for all elements. In fact, it is well known that USN convert more efficiently liquid samples into aerosol suitable for ICP analysis. The sampling rate of aerosol generation is typically up to ten times better than that of conventional pneumatic nebulizers.
The objective of this study was to evaluate the potential of an axial view ICP spectrometer equipped with an ultrasonic nebulizer for the determination of six trace elements often analyzed in plant samples ( $\mathrm{As}, \mathrm{Cd}, \mathrm{Co}, \mathrm{Cr}, \mathrm{Ni}$, and $\mathrm{Pb}$ ). Plant samples have been analyzed with radial view ICP and USN [10] and with axial view system and pneumatic nebulizer [9] but no reports could be found for axial-view ICP equipped with USN. Problems for the analyses of many different types of samples are, then, still unknown in this instrumental configuration.

Chemical matrix effects must be considered and removed to obtain accurate analytical results. The nature and causes of matrix effects have been widely discussed in the literature and have been reviewed by Olesik [11]. It is assumed that interferences in ICP result from changes in the excitation conditions in the plasma itself such as electron number density and ionization temperatures. It can result a significant analytical error for samples with high concentration of dissolved solids such as mineralized plant solutions. Interferences of this type have been reported in axial-view ICP equipped with pneumatic nebulizer and can at times be quite severe $[5,6,9]$. On other hand, previous studies have also reported matrix effects in radial view system with USN $[10,12-14]$. Consequently, the use of ultrasonic nebulization on an axial view ICP represents probably a very unfavorable case for the heaviest matrix. 
A synthetic stock matrix solution was prepared containing the major elements ( $\mathrm{K}, \mathrm{Ca}, \mathrm{Mg}, \mathrm{Na}, \mathrm{P}, \mathrm{Fe}$ and $\mathrm{Mn}$ ) at concentrations encountered in plant digests. The influence of this matrix on the ion and atom lines intensities of the six trace elements was investigated at various concentrations. This simulation method has been used by Hoenig et al. [10] for a radial ICP equipped with ultrasonic nebulizer. The interferences affecting the measurements were discussed and minimized as far as possible. The aim of this simulation was also to determine the effect of the adjustable parameters such as power, nebulization pressure or uptake flow rate on the inter-element effects in plant samples. Next, the accuracy of the optimized analytical method was controlled using a plant material with increasing spikes of a trace elements standard solution.

\section{Experimental}

\section{Apparatus}

The ICP-AES instrument used was a Varian Liberty Series II vacuum spectrometer with an SPS-5 autosampler. The instrument was equipped with a standard one-piece low flow extended torch with quartz injector tube (2.3 mm diameter). The axial-viewed torch system has a cooled cone interface, eliminating the need for a shear gas, reducing interference, and improving the linear dynamic range. An independent ultrasonic nebulizer U-6000AT+ (CETAC Technologies, USA) equipped with a two-stage desolvation system was used. The liquid sample is pumped onto the face of the piezoelectric transducer driven ultrasonic frequencies where it is converted to a fine and dense aerosol. The nebulizer gas flow transports the wet aerosol through a heated U-tube where the solvent is vaporized. Solvent vapors are then condensed by the thermo-electric cooler and removed by the drain pump to the waste. The sample output is sent directly to the ICP.

The maximization of the signal to background ratios was chosen to adjust the ICP parameters in the initial method and to begin measurements with the highest analytical sensitivity. Details of experimental conditions used in this study are summarized in Table I. The wavelengths chosen were the most sensitive among these without spectral interference. Details of element parameters are given in Table II.

\section{Interference studies}

Interference studies were performed on the six analytes (As, $\mathrm{Cd}, \mathrm{Co}, \mathrm{Cr}, \mathrm{Ni}$ and $\mathrm{Pb}$ ) present at the concentration of $16 \mu \mathrm{g} . \mathrm{L}^{-1}$ in the matrix solutions. The solutions were issued from a stock solution containing the main matrix elements as than encountered in mineralized plant samples: K 500 mg.L ${ }^{-1}$, Ca 250 mg.L $\mathrm{L}^{-1}$, Mg 80 mg.L ${ }^{-1}$, P 80 mg.L $\mathrm{L}^{-1}$, $\mathrm{Na} 40 \mathrm{mg} . \mathrm{L}^{-1}$, Fe $30 \mathrm{mg} . \mathrm{L}^{-1}$ and Mn $20 \mathrm{mg} . \mathrm{L}^{-1}$. Such concentrations are perhaps too high to represent real sample; in plant samples they may attain about half of these values on average. Parts of the synthetic matrix solution were added
Table I. Analytical parameters.

\begin{tabular}{|c|c|c|}
\hline & initial program & modified program \\
\hline Generator Frequency $(\mathrm{MHz})$ & 40.68 & 40.68 \\
\hline PMT voltage $(\mathrm{V})$ & 900 & 900 \\
\hline Nebulization pressure (Kpa) & 220 & 200 \\
\hline Pump rate $(\mathrm{rpm})$ & 25 & 25 \\
\hline Plasma gas flow (L.min ${ }^{-1}$ ) & 15 & 15 \\
\hline Auxiliary gas flow (L.min ${ }^{-1}$ ) & 2.25 & 2.25 \\
\hline Background correction & Dynamic mode & Dynamic mode \\
\hline Power $(\mathrm{kW})$ & 1.0 & 1.4 \\
\hline USN temperatures $\left({ }^{\circ} \mathrm{C}\right)$ & $140 / 2$ & $140 / 2$ \\
\hline
\end{tabular}

to aliquots of the trace multi-element solution in the following proportion: $0 \%$ (pure trace multi-element solution), $10 \% \mathrm{v} / \mathrm{v}, 20 \% \mathrm{v} / \mathrm{v}, 40 \% \mathrm{v} / \mathrm{v}, 60 \% \mathrm{v} / \mathrm{v}$ and $80 \% \mathrm{v} / \mathrm{v}$ before completion with distilled water to a constant volume. Each solution was acidified to $5 \% \mathrm{v} / \mathrm{v}$ with concentrated nitric acid. Analyte signals were measured in triplicate. Relative intensities were expressed as the ratios of the intensities obtained in the matrix solutions to this obtained in the pure solution. This procedure allows determining the effects of progressively increasing amounts of plant matrix on the analytical response of trace elements studied. All reagents were analytical grade. All vessels were washed with $10 \% \mathrm{v} / \mathrm{v}$ $\mathrm{HNO}_{3}$ and rinsed with distilled water before use.

\section{Recovery studies}

The accuracy of the method was ultimately controlled using a usually cultivated plant sample (hay powder). The sample was digested many times with blanks. Two additions of a standard solution containing $400 \mu \mathrm{g} . \mathrm{L}^{-1}$ of the researched elements were added in certain solutions (respectively $1 \mathrm{~mL}$ and $5 \mathrm{~mL}$ to obtain final added concentrations of $4 \mu \mathrm{g} . \mathrm{L}^{-1}$ and $\left.20 \mu \mathrm{g} . \mathrm{L}^{-1}\right)$. In final, we have three different plant digestion solutions in triplicate, one without addition and two with addition in the volumetric flasks.

For digestion, dry plant sample $(1.0 \mathrm{~g})$ was weighed in to a $250 \mathrm{~mL}$ Pyrex glass tube. Then $5 \mathrm{~mL}$ nitric acid $\left(\mathrm{HNO}_{3}\right.$ $65 \%$ Baker analyzed) were added. After 16 hours (overnight) of cold digestion, $10 \mathrm{~mL}$ of hydrogen peroxide $\left(\mathrm{H}_{2} \mathrm{O}_{2} 30 \%\right.$ Baker analyzed) were added. The tubes were equipped with a cooling system and heated with reflux during a $2.5 \mathrm{~h}$ period. The acid mixture was thereafter filtered through ashless filter paper into a $100 \mathrm{~mL}$ volumetric flask and made up with distilled water.

The ICP-AES instrument is calibrated with a blank and three multi-element standard solutions prepared from commercially available 1000 g.L $\mathrm{L}^{-1}$ stock solutions (Merck Titrisol). The final concentrations in the standard solutions (acidified to $5 \% \mathrm{v} / \mathrm{v}$ with nitric acid) were respectively 400, 200 and 100 $\mu \mathrm{g} . \mathrm{L}^{-1}$. The linearity of the standards was satisfactory for all species $\left(r^{2} \geq 0.995\right)$ over this concentration range. 
Table II. Spectroscopic data.

\begin{tabular}{|c|c|c|c|c|c|c|c|}
\hline Element & $\begin{array}{c}\text { Wavelenght } \\
\mathrm{nm}\end{array}$ & $\begin{array}{c}\text { Atom/Ion } \\
\text { I/II }\end{array}$ & $\begin{array}{l}\text { grating } \\
\text { order }\end{array}$ & $\begin{array}{c}\text { integration } \\
\text { time } \\
\text { sec }\end{array}$ & $\begin{array}{c}\text { Ionization } \\
\text { potential } \\
\mathrm{eV}\end{array}$ & $\begin{array}{c}\text { Excitation } \\
\text { potential } \\
e V\end{array}$ & $\begin{array}{c}\text { Total } \\
\text { energy } \\
e V\end{array}$ \\
\hline As & 188.979 & I & 1 & 10 & 9.81 & 6.57 & 6.57 \\
\hline $\mathrm{Cd}$ & 214.438 & II & 3 & 3 & 8.99 & 5.79 & 14.78 \\
\hline $\mathrm{Cd}$ & 228.802 & I & 3 & 3 & 8.99 & 5.43 & 5.43 \\
\hline $\mathrm{Co}$ & 345,350 & I & 1 & 10 & 7.86 & 3.59 & 3.59 \\
\hline $\mathrm{Cr}$ & 267.716 & II & 3 & 3 & 6.77 & 4.64 & 11.40 \\
\hline $\mathrm{Cr}$ & 357,869 & I & 2 & 5 & 6.77 & 3.46 & 3.46 \\
\hline $\mathrm{Ni}$ & 221.647 & II & 3 & 3 & 7.64 & 5.60 & 13.24 \\
\hline $\mathrm{Ni}$ & 231.604 & II & 3 & 3 & 7.64 & 5.36 & 12.99 \\
\hline
\end{tabular}

\section{Results and discussion}

\section{Interference studies}

In figure 1 , the relative intensities of analytes are presented depending on the addition rate of the matrix solution. Accurate analyses require that any change in the plant matrix composition does not result in a significant variation in the analytical signal; a $5 \%$ rate as error is acceptable for a usual routine analysis. With the exception of As, the effects shown depressions of the analyte emission intensities with an increasing amount of matrix in the plasma. In the most unfavorable cases it may attain about $25 \%$ depression in the presence of the heaviest matrix. For the analytical signal of As, concomitants cause an enhancement effect for all matrices used.
Alternative wavelengths, slightly less sensitive, were tested for $\mathrm{Cd}, \mathrm{Co}, \mathrm{Cr}$ and $\mathrm{Ni}$. Spectroscopic data are also given in table II. Compared with figure 1, figure 2 indicated different behavior of the atomic and ionic spectral lines of the same analyte in the presence of the matrix. Largest depressions in the ionic emission intensities occurred and were more severe for spectral lines with high ionization and excitation potentials (Cd $214.438 \mathrm{~nm}$ ). This is in accordance with previous observations in axial view ICP [6,9]. Enhancements in the atomic emission intensities occurred in the plasma and are largest for spectra lines where less excitation energy is required $(\mathrm{Cr} 357.869 \mathrm{~nm}$ and Co $345.350 \mathrm{~nm}$ ). These improvements appeared for the lowest matrix solution (10\%) but were also depressed with an increasing amount of matrix.

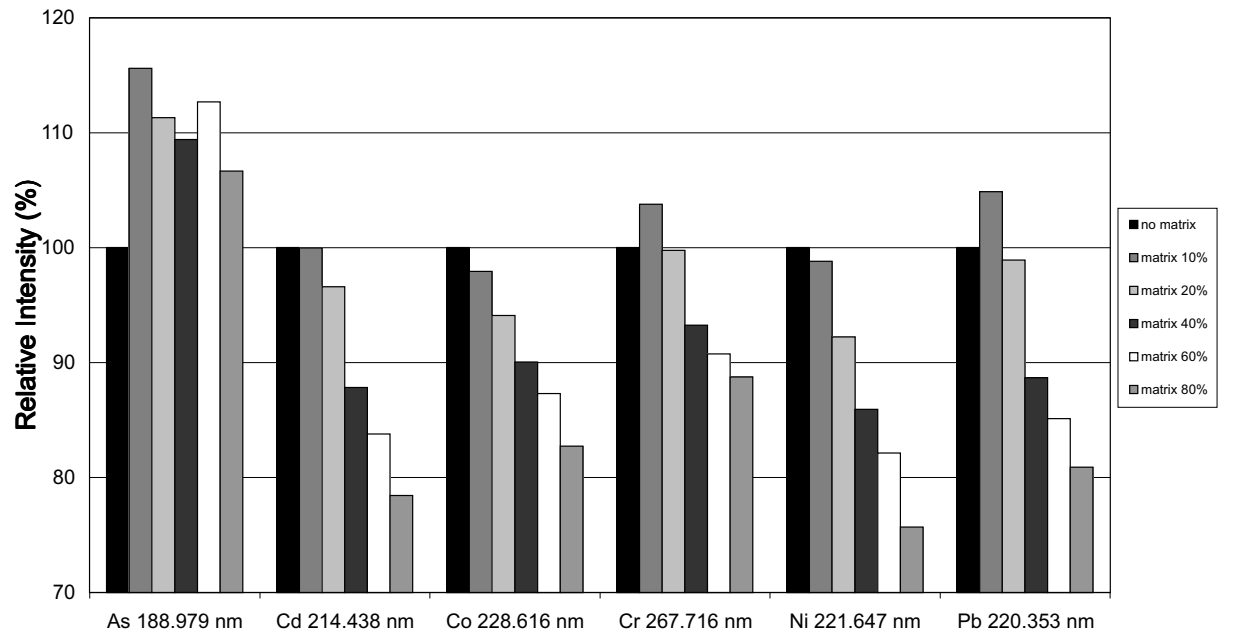

Fig. 1. Effect of the matrix concentration on emission signal recoveries of the six trace elements. 


\section{Original articles}

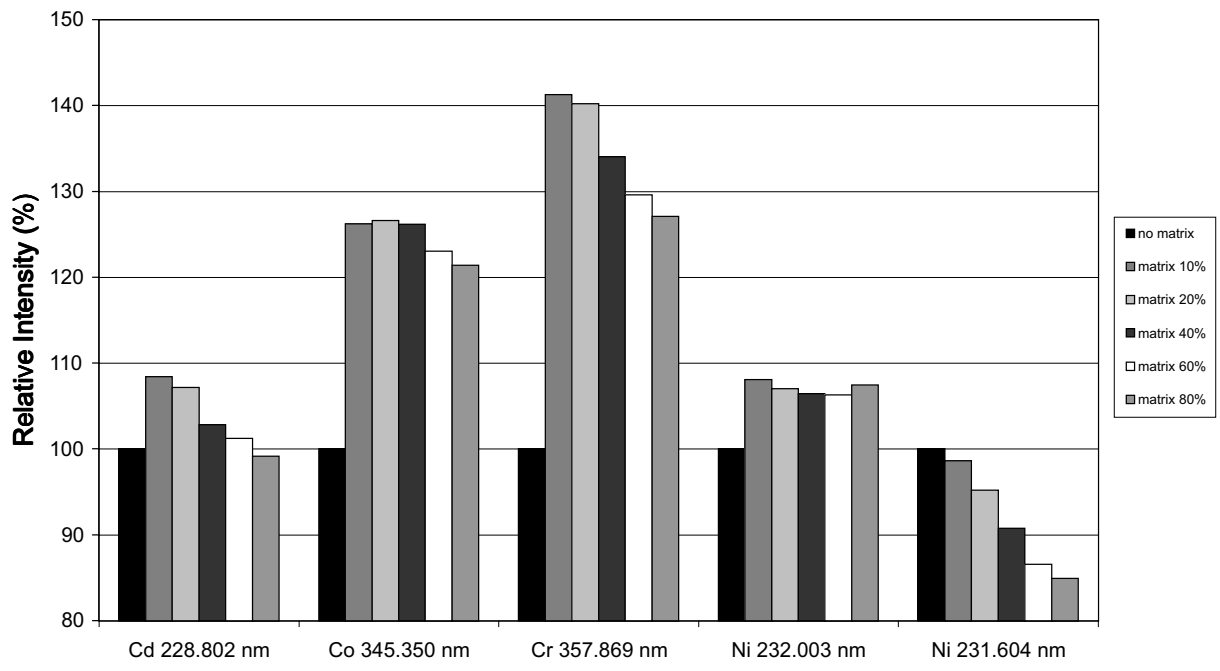

Fig. 2. Effect of the matrix concentration on emission signal recoveries of some trace elements for alternative wavelengths.
However, this first optimized method was unsatisfactory. A way to obtain robust conditions is to vary power supply, aerosol flow rate and carrier gas flow rate $[5,6,9,15]$; the transfer of energy between plasma and sample depend strongly on these parameters. The power influences the energy available in the plasma. The aerosol flow rate can be adjusted by the setting of speed of peristaltic pump and influences the amount of dry aerosol in the plasma. The gas flow rate can be controlled by the nebulization pressure and influences the residence time of the sample in the plasma.

Figure 3 presents the effects of various powers supplies on the ionic line relative intensities of several trace elements for the $80 \%$ matrix solution. In all cases, the effects were decreased as power increases. At $1.4 \mathrm{~kW}$, the analytical signals were satisfactory for routine analysis (relative intensity above $95 \%)$. Only the most energetic line (Cd $214.438 \mathrm{~nm})$ remained to low but very nearby of the limit $(93.8 \%)$. Figures 4 and 5 present the effect of power on the atomic spectral lines for the $80 \%$ and $10 \%$ matrix solution respectively. The relative intensities shown enhancements as power is increased especially for elements with low excitation potentials such as $\mathrm{Cr}$ or $\mathrm{Co}$. Spectral lines originating from states with high excitation energies (Cd $228.802 \mathrm{~nm}$ and As $188.979 \mathrm{~nm}$ ) were less affected and gave satisfactory results for the slight power supplies (below $1.0 \mathrm{~kW}$ ).

In figure 6 , the effects of the $80 \%$ matrix solution on the analytical signals are function of various pump speed. The measurements were performed at $1.3 \mathrm{~kW}$ power supply for ionic lines and $0.8 \mathrm{~kW}$ for atomic lines. The influence was very sensitive below $20 \mathrm{rpm}$ whatever the nature of the spectra line (ionic or atomic). As the solution uptake rate decreased, interferences improved the emission signals. Under these conditions, the influence of the solution flow rate only, was not adequate contrary to the studies with pneumatic nebulizer [9]. Figure 7 shows the effects of the $80 \%$ matrix solution on the analytical signals of several elements as function of various nebulizer pressures. The

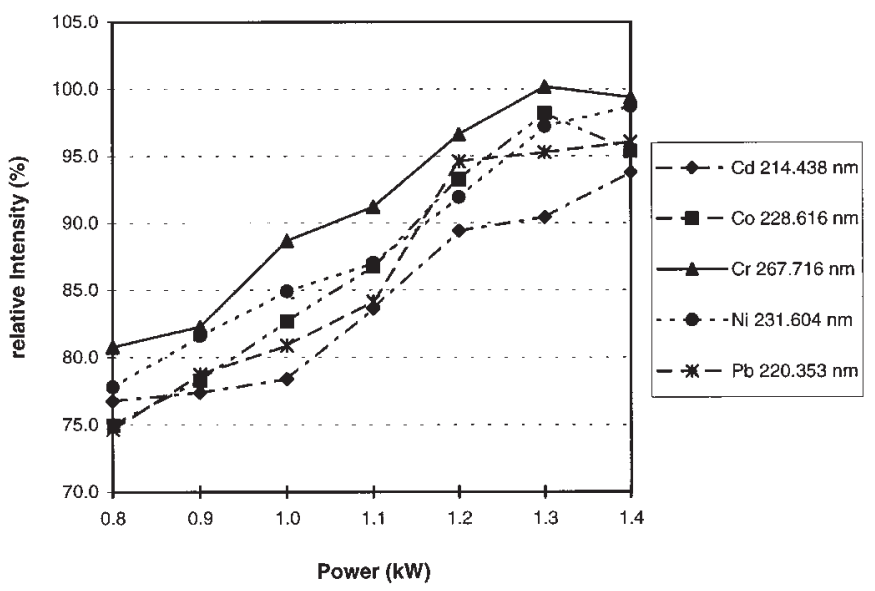

Fig. 3. Effect of the power supply on emission signal recoveries of the $80 \%$ matrix solution for the ionic wavelengths of elements (Pump speed: $25 \mathrm{rpm}$, Nebulization pressure: $220 \mathrm{kPa}$ ).

measurements were performed at $1.2 \mathrm{~kW}$ power supply. The same effects occurred than with the pump speed. The enhancements of emission intensities were sensitives for the slight pressures (below $200 \mathrm{kPa}$ ). The limitation of interferences on the trace elements analysis was obtained especially with great power supply $(1.4 \mathrm{~kW})$ for ionic lines.

\section{Discussion}

USN decreased the amount of water entering into the plasma with a desolvation system and increased the available plasma energy compared to pneumatic nebulizer [9]. Nevertheless, a substantial mass of particles was introduced into the plasma in the presence of any high salt plant matrix 


\section{Original articles}

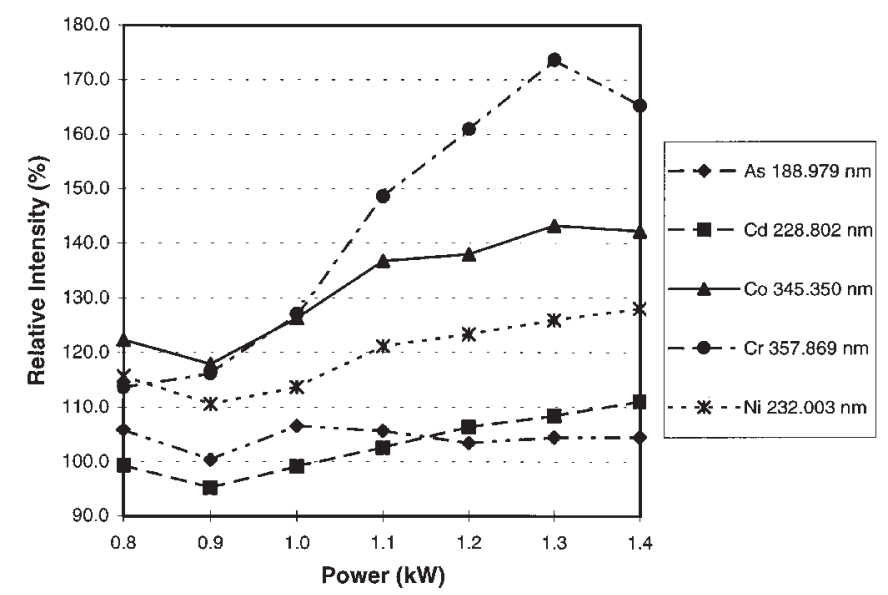

Fig. 4. Effect of the power supply on emission signal recoveries of the $80 \%$ matrix solution for the atomic wavelengths of elements (Pump speed: $25 \mathrm{rpm}$, Nebulization pressure: $220 \mathrm{kPa}$ ).

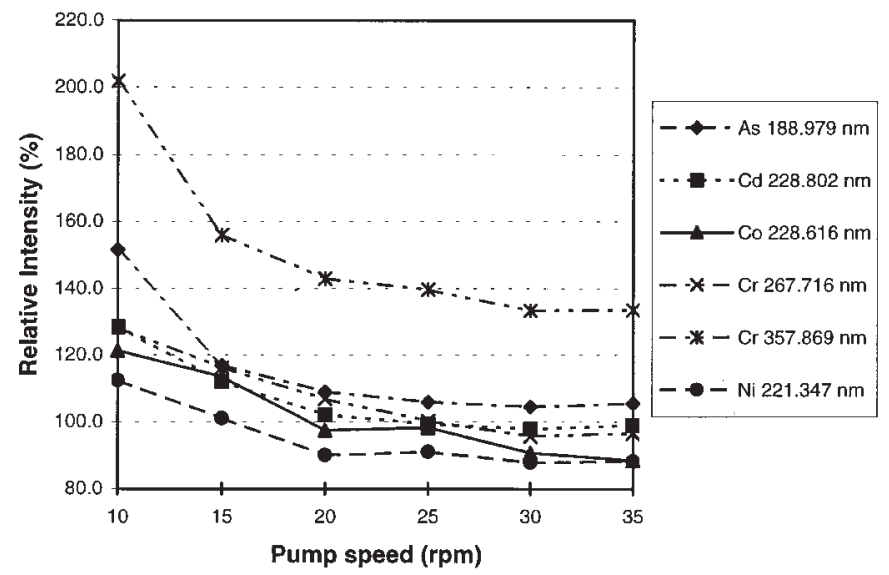

Fig. 6. Effect of the pump speed on emission signal recoveries of the $80 \%$ matrix solution for some elements (Power: $1.3 \mathrm{~kW}$ for the ionic wavelengths, Power: $0.8 \mathrm{~kW}$ for the atomic wavelengths, Nebulization pressure: $220 \mathrm{kPa}$ ).

type. Particles were distributed across the central channel of the plasma [16] and energy was absorbed through particle vaporization, dissociation, ionization and excitation. This would produce a significant reduction in ionization temperature and in electron population [16,17]. When non-robust conditions were used, the excitation step lacks energy. This cooling effect contributed to decrease analytical line intensities.

Plant samples were typically the case of easily ionizable elements (EIEs) as matrix effects [5,6,18-24] and analytes signals were affected by the presence of high concentrations

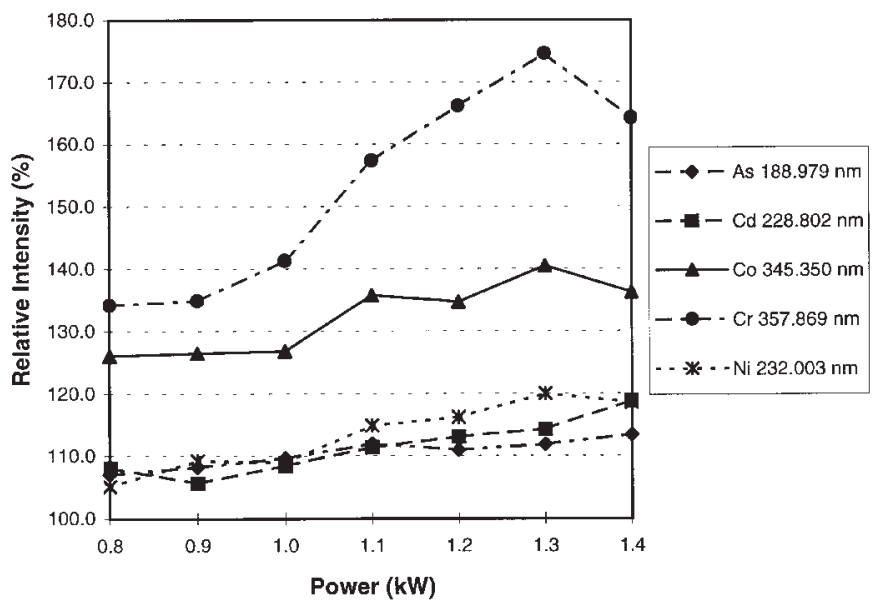

Fig. 5. Effect of the power supply on emission signal recoveries of the $10 \%$ matrix solution for the atomic wavelengths of elements (Pump speed: $25 \mathrm{rpm}$, Nebulization pressure: $220 \mathrm{kPa}$ ).

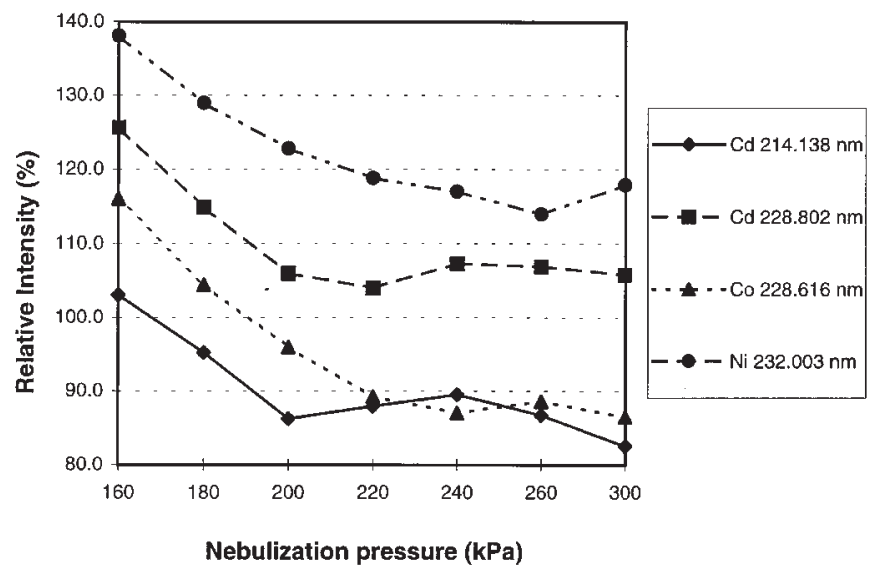

Fig. 7. Effect of the nebulization pressure on emission signal recoveries of the $80 \%$ matrix solution for some elements (Power: $1.2 \mathrm{~kW}$, Pump speed: $25 \mathrm{rpm}$ ).

of elements efficiently ionized such as $\mathrm{K}, \mathrm{Ca}$ or $\mathrm{Mg}$. EIEs are strongly ionized in the plasma and cause enhancement of electron number density in the coolest plasma zones [24] which probably increase size with the particles effect for highest matrix concentrations. Thus, EIEs cause a shift in the relative number of atoms and ions towards atom by ionelectron recombination reactions $[18,21]$. The axial dependence of analyte emission intensities in the presence of an excess of EIEs was investigated previously [19,20,22]. It can be resumed that ionic lines of analytes are decreased. The depressions tend to be more severe for less easily ionized 


\section{Original articles}

elements. Enhancements in the atomic emission intensities occurred in the coolest plasma zones and are largest for easily ionized elements. The experimental results (Fig. 1-2) led to the same observations. The EIEs effect appeared for few matrix amounts $(10 \%)$ and was depressed by the particle effect for the highest matrix concentrations.

Increasing the input power resulted in a corresponding increase temperatures at all location in the plasma and appeared to equalize the electron density in the central channel [25]. The energy transfer between the plasma and the species were more completed and more particles should be completely vaporized. Under some circumstances, the analytical ionic line intensities were restored but EIEs effect remained severe for atomic emission intensities and it was difficult to found an explanation. High power supply and high matrix concentration were two antagonist phenomenons, which led perhaps to larger recombination reaction regions. High power accelerated also the kinetic of the ionelectron recombination reactions.

Decreasing the sample uptake rate or the nebulization pressure leads generally to minimize the plasma energy absorption and, then, the matrix effects. However, the relative intensities of analyte lines for the $80 \%$ matrix solution increase rapidly. Boumans and deBoer [12] have observed this phenomenon for $\mathrm{Zn}$ with presence or absence of different concentrations of $\mathrm{KCl}$. They interpret this behavior in terms of a loss in the water drained from the condenser for the pure aqueous solution. In fact, if the pump speed and the nebulization pressure influenced the amount of aerosol and it residence time in the plasma, they influenced also the amount of aerosol and it residence time in the USN desolvation system. The solvent elimination became very efficient, especially when no matrix was present. The dried aerosol with matrix might contain water attached to the salt particles and was less affected. Many workers [26-30] indicated that water plays a very important role in excitation characteristics of the plasma. The absence of water resulted in a poor energy transfer in the plasma for the solution without matrix and, then, an increasing in the relative intensities.
The effect might be masked when more amount of water is present in the plasma via larger pump speed or larger nebulization pressure.

\section{Recovery studies}

The possible extends of these interferences and their correction was verified by the analysis of the six trace elements studied in plant sample with addition of standard solution. Results with the initial analytical program were unsatisfactory for the majority of trace elements (Tab. III). The depressions observed for the ionic spectra lines varied between $8.1 \%(\mathrm{Cr})$ and $27.3 \%(\mathrm{~Pb})$ for the $4 \mu \mathrm{g} . \mathrm{L}^{-1}$ addition and between $12.1 \%(\mathrm{Cd})$ and $20.9 \%(\mathrm{~Pb})$ for the $20 \mu \mathrm{g} . \mathrm{L}^{-1}$ addition. Only As signals appeared as unaffected by the matrix presence. This was in accordance with the interference studies.

To remove the matrix effects, a second method was edified with different experimental conditions of the ICP based on the simulation results (Tab. I). Like this, previously reported interferences for the ionic spectral lines became negligible (Tab. IV). In all cases, the analytical results obtained for the reference plant sample were comparable to the corresponding spites (errors $<5 \%$ except Cr: $5.1 \%$ ). Conversely, recoveries were logically unacceptable for the atomic spectral lines (Table V). However, each analyze of plant material may be routinely considered. Table VI shows the detection limits obtained for both methods. The detection limits were calculated as three times the standard deviations of the blanks which were determined by measuring 10 times a sample of distilled water in $5 \% \mathrm{v} / \mathrm{v} \mathrm{HNO}_{3}$. It was clear that the performances attained were in the range of graphite furnace atomic absorption spectrometry (GFAAS). It should be mentioned that matrix effects decreased the signal to background ratios and can affected slightly the detection limits. Consequently, the indicated values were the theoretical limits which cannot be exceeded in practice.

Table III. Recovery in $\mu \mathrm{g} . \mathrm{L}^{-1}$ of addition in the plant solutions with the initial ICP program.

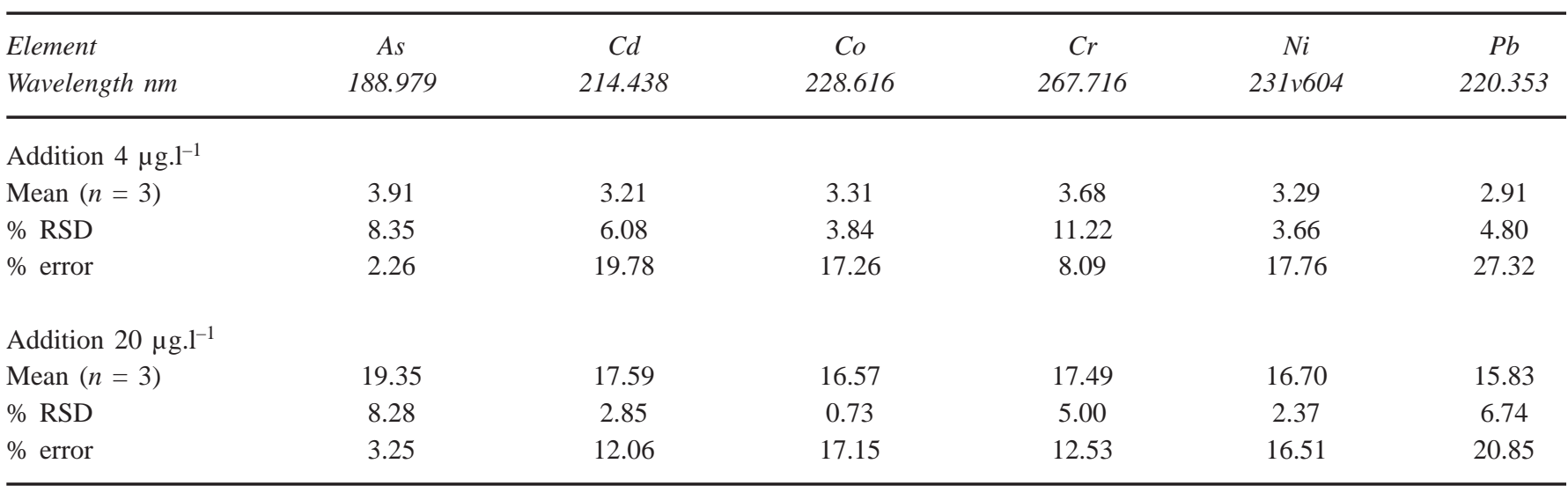




\section{Original articles}

Table IV. Recovery in $\mu \mathrm{g} . \mathrm{L}^{-1}$ of addition in the plant solutions with the modified ICP program.

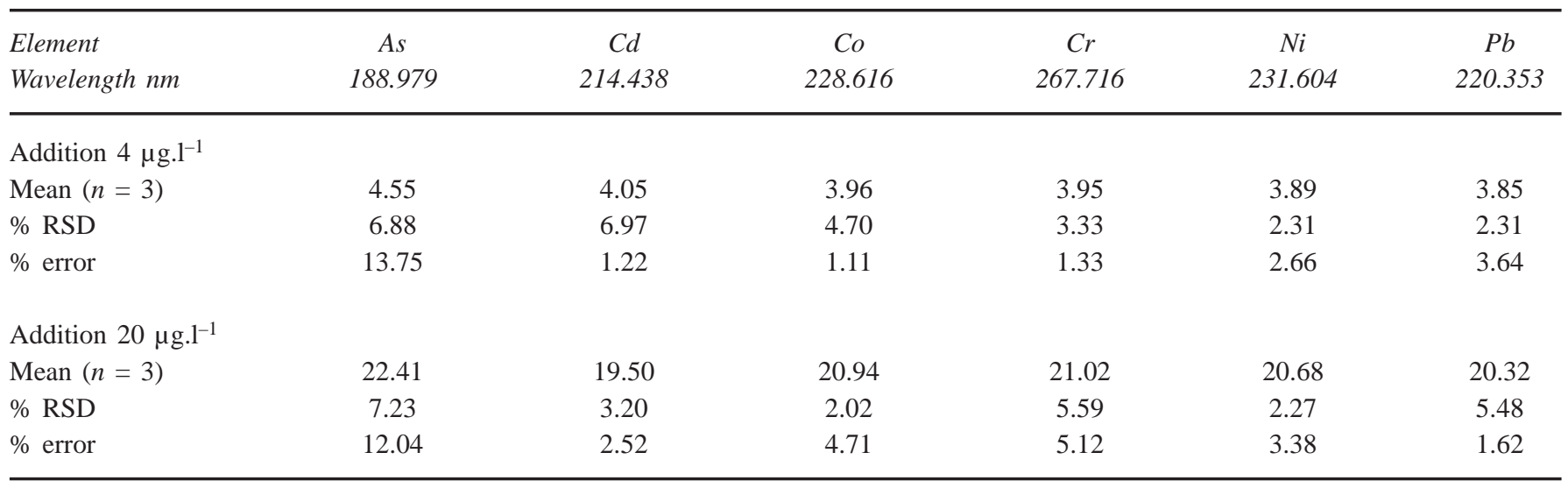

Table V. Recovery in $\mu \mathrm{g} . \mathrm{L}^{-1}$ of addition in the plant solutions for atomic spectra lines with the modified ICP program.

\begin{tabular}{lcccc}
\hline $\begin{array}{l}\text { Element } \\
\text { Wavelength } \mathrm{nm}\end{array}$ & $\mathrm{Cd}$ & $\mathrm{Co}$ & $\mathrm{Cr}$ & $\mathrm{Ni}$ \\
& 228.802 & 345.350 & 357.869 & 232.003 \\
\hline Addition $4 \mu \mathrm{g} . \mathrm{l}^{-1}$ & & & & \\
Mean $(n=3)$ & 4.40 & 5.28 & 5.92 & 5.14 \\
\% RSD & 8.96 & 7.57 & 5.26 & 0.95 \\
\% error & 9.99 & 31.93 & 47.92 & 28.56 \\
& & & & \\
Addition 20 $\mu \mathrm{gg} . \mathrm{l}^{-1}$ & & & & \\
Mean $(n=3)$ & 21.69 & 23.69 & 25.70 & 22.43 \\
\% RSD & 2.08 & 2.20 & 2.92 & 0.56 \\
\% error & 8.43 & 18.46 & 28.48 & 12.15 \\
\hline
\end{tabular}

Table VI. Detection limits in $\mu \mathrm{g} . \mathrm{L}^{-1}$ for the two ICP methods.

\begin{tabular}{lccc}
\hline Element & Wavelenght $(\mathrm{nm})$ & initial program & modified program \\
\hline $\mathrm{As}$ & 188.979 & 0.976 & 1.161 \\
$\mathrm{Cd}$ & 214.438 & 0.051 & 0.046 \\
$\mathrm{Co}$ & 228.616 & 0.105 & 0.074 \\
$\mathrm{Cr}$ & 267.716 & 0.200 & 0.321 \\
$\mathrm{Ni}$ & 231.604 & 0.233 & 0.428 \\
$\mathrm{~Pb}$ & 220.353 & 0.617 & 0.696 \\
\hline
\end{tabular}

\section{Conclusion}

The results suggested that axial view ICP-AES equipped with ultrasonic nebulizer could become a suitable analytical tool for the routine determination of trace elements in digests of plant samples provided that the matrix interferences are corrected. In this study, the plant matrix effects were strongly related to analyte excitation potentials and were identified as a combination of particles and EIEs individual effects in the axial zone of the plasma. The dissociation of particles in free atoms and ions cooled the plasma and decreased the fraction of analytes that were excited. The ionization of EIEs changed the ion/atom ratio toward atom by ion-electron recombination reactions. Particles and EIEs had then the same effect on the ionic line intensities and led to their depressions. On the other hand, particle effect competed with EIEs effect on the atomic spectra lines. The data shown that the EIEs enhancement is stronger than the particle depression.

Accurate measurements were restored by using operating ICP parameters leading to an efficient energy transfer between the plasma and the sample. It is recommended to use a generator power higher than $1.3 \mathrm{~kW}$. The ion emission signals of analytes were so depressed less than $5 \%$, which is acceptable for routine analysis. Moderate power $(1.0 \mathrm{~kW})$ could be used for the more energetic atomic spectral lines (such as As $188.979 \mathrm{~nm}$ ). It is recommended also to control the flow rate of aerosol entering in the plasma (pump speed $>20 \mathrm{rpm}$ and nebulization pressure > $200 \mathrm{kPa}$ ). Contrary to the use of pneumatic nebulizer, a decrease of the sample flow rate or in the carrier gas flow rate increased the matrix effect in the plasma.

However, detection limits attained with axial ICP and ultrasonic nebulization are in the range of GF-AAS. Due to improved sensitivity, samples may be often diluted and matrix effects consequently minimized. The concentration of concomitants encountered in plant samples was relatively low and does not correspond to the maximum matrix influence that could be obtained for other environmental samples such as soils or wastes.

\section{References}

1. Huang, C.L.; Schulte, E E. Commun. Soil Sci. Plant Anal. 1985, 16, 943-958. 


\section{Original articles}

2. Bowman, R. A. Commun. Soil Sci. Plant Anal. 1989, 20, 539553.

3. Turner, M. D; Brooks, P. D. Commun. Soil Sci. Plant Anal. 1992, 23, 559-568.

4. Masson, P.; Esvan, J.-M. Analusis 1995, 23, 437-440.

5. Dubuisson, C.; Poussel, E.; Mermet, J. M. J. Anal. At. Spectrom. 1997, 12, 281-286.

6. Brenner, I. B.; Zander, A.; Cole, M.; Wiseman, A. J. Anal. At. Spectrom. 1997, 12, 897-906.

7. Raven, K. P.; Reynolds, J. W.; Loeppert, R. H. Commun. Soil Sci. Plant Anal. 1997, 28, 237-257.

8. Davies, J.; Dean, J. R.; Snook, R. D. Analyst 1985, 110, 535540.

9. Masson, P. Spectrochim. Acta B 1999, 54, 603-612.

10. Hoenig, M.; Baeten, H.; Vanhentenrijk, S.; Ploegaerts, G.; T. Bertholet, T. Analusis 1997, 25, 13-19.

11. Olesik, J. W. Anal. Chem. News \& Features 1996, 469A474A.

12. Boumans, P. W. J. M.; De Boer, F. J. Spectrochim. Acta B 1976, 31, 355-375.

13. Trassy, C.; Mermet J. M., Les applications analytiques des plasmas HF; Technique et Documentation, Lavoisier: Paris, 1984.

14. Clifford, R.H.; Sohal, P.; Liu, H.; Montraser, A. Spectrochim. Acta B, 1992, 47,1107-1122.

15. Mermet, J.M. Anal. Chim. Acta 1991, 250, 85-94.

16. Olesik, J. W.; Smith, L. J.; Williamsen, E. J. Anal. Chem. 1989, 61, 2002-2008.
17. Hobbs, S. E.; J. W. Olesik, J. W. Spectrochim. Acta B 1993, $48,817-833$.

18. Blades, M. W.; Horlick, G. Spectrochim. Acta B 1981, 36, 861880.

19. Olesik, J. W.; Williamsen, E. J. Appl. Spectrosc. 1989, 43, 1223-1232.

20. Gillson, G.; Horlick, G. Spectrochim. Acta B 1986, 41, 619624.

21. Thompson, M.; Ramsey, M. H. Analyst 1985, 110, 1413-1422.

22. Tripkovic, M. R.; Holclajtner-Antunovic, I. D. J. Anal. At. Spectrom. 1993, 8, 349-357.

23. Holclajtner-Antunovic, I. D.; Tripkovic, M. R. J. Anal. At. Spectrom. 1993, 8, 359-365.

24. Romero, X.; E. Poussel, E.; Mermet, J. M. Spectrochim. Acta B 1997, 52, 495-502.

25. Caughlin, B. L.; Blades, M. W. Spectrochim. Acta B 1984, 39, 1583-1602.

26. Tang, Y. Q.; Trassy, C. Spectrochim. Acta B 1986, 41, 143150.

27. Long, S. E.; Browner, R. F. Spectrochim. Acta B 1986, 41, 639-649.

28. Long, S. E.; Browner, R. F. Spectrochim. Acta B 1988, 43, 1461-1471.

29. Caughlin, B. L.; Blades, M. W. Spectrochim. Acta B 1987, 42, 353-360.

30. Nowak, S.; van der Mullen, J. M. A.; van Lammeren, A. C. A. P.; Schram, D. C. Spectrochim. Acta B 1989, 44, 411-418. 